\title{
The part of the solar spectrum with the highest influence on the formation of SOA in the continental boundary layer
}

\author{
M. Boy and M. Kulmala \\ Dept. of Physical Sciences, University of Helsinki, P.O. Box 64, FIN-00014, UHEL, Finland \\ Received: 25 April 2002 - Published in Atmos. Chem. Phys. Discuss.: 9 September 2002 \\ Revised: 14 November 2002 - Accepted: 15 November 2002 - Published: 28 November 2002
}

\begin{abstract}
The relationship between nucleation events and spectral solar irradiance was analysed using two years of data collected at the Station for Measuring Forest EcosystemAtmosphere Relations (SMEAR II) in Hyytiälä, Finland. We analysed the data in two different ways. In the first step we calculated ten nanometer average values from the irradiance measurements between 280 and $580 \mathrm{~nm}$ and explored if any special wavelengths groups showed higher values on event days compared to a spectral reference curve for all the days for 2 years or to reference curves for every month. The results indicated that short wavelength irradiance between 300 and $340 \mathrm{~nm}$ is higher on event days in winter (February and March) compared to the monthly reference graph but quantitative much smaller than in spring or summer. By building the ratio between the average values of different event classes and the yearly reference graph we obtained peaks between 1.17 and 1.6 in the short wavelength range (300-340 nm). In the next step we included number concentrations of particles between 3 and $10 \mathrm{~nm}$ and calculated correlation coefficients between the different wavelengths groups and the particles. The results were quite similar to those obtained previously; the highest correlation coefficients were reached for the spectral irradiance groups 3-5 (300-330 nm) with average values for the single event classes around 0.6 and a nearly linear decrease towards higher wavelengths groups by $30 \%$. Both analyses indicate quite clearly that short wavelength irradiance between 300 and 330 or $340 \mathrm{~nm}$ is the most important solar spectral radiation for the formation of newly formed aerosols. In the end we introduce a photochemical mechanism as one possible pathway how short wavelength irradiance can influence the formation of SOA by calculating the production rate of excited oxygen. This mechanism shows in which way short wavelength irradiance can influence the formation of new particles even though the absolute values are one to two magnitudes smaller compared to irradiance
\end{abstract}

Correspondence to: M. Boy (Michael.Boy@helsinki.fi) between 400 and $500 \mathrm{~nm}$.

\section{Introduction}

Atmospheric aerosols are amongst other constituents responsible for light scattering, cloud formation and heterogeneous chemical effects and they are a key factor in balancing global climate (e.g. Houghton et al., 1996). There are two main sources for atmospheric aerosols: the emission of particles natural or anthropogenic - and the gas-to-particle transfer by homogeneous or heterogeneous nucleation of supersaturated vapours. The formation of secondary aerosols has been extensively studied in different environments in the last decades (e.g. free troposphere: Clarke, 1993; marine: Raes et al., 1997; coastal: O'Dowd et al., 1998; continental boundary layer: Kulmala et al., 2001b; Nilsson et al., 2001). Several nucleation mechanisms have been developed in the past few years to explain the observations of particle bursts in the atmosphere. The best understood way up till now is the binary nucleation of $\mathrm{H}_{2} \mathrm{SO}_{4}$ and $\mathrm{H}_{2} \mathrm{O}$ (Kulmala et al., 1998) or the ternary nucleation of $\mathrm{H}_{2} \mathrm{O}, \mathrm{NH}_{3}$ and $\mathrm{H}_{2} \mathrm{SO}_{4}$ (Korhonen et al., 1999). According to Kulmala et al. (2000) binary nucleation theory is not able to predict the observed nucleation rates in the atmosphere at typical tropospheric sulphuric acid concentrations $\left(10^{5}--10^{7} \mathrm{~cm}^{-3}\right.$, Weber et al., 1998; Weber et al., 1999). Ternary nucleation, however, gives significantly higher nucleation rates and thus can better predict the formation of new particles at typical tropospheric conditions (ammonia at a level of a few ppt). Kulmala et al. (2000) suggest that nucleation occurs almost everywhere in the atmosphere, at least during the daytime and leads to a reservoir of thermodynamically stable clusters (TSCs), which under certain conditions grow to detectable sizes. However we still do not exactly know under what kind of meteorological and physical conditions the growth of these TSCs will occur and which precursor gases are necessary. 


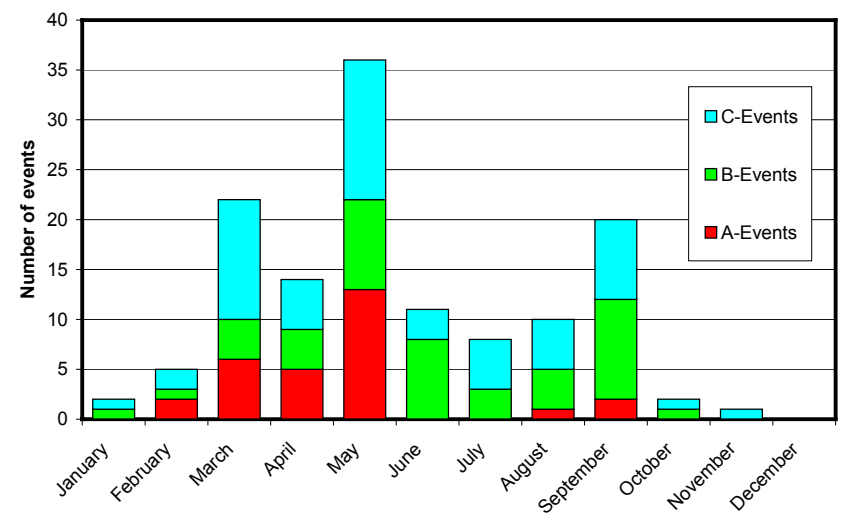

Fig. 1. Monthly distribution of event classes for 2000 and 2001.

In our last publication (Boy and Kulmala, 2002) we suggested that UVA solar radiation is one key parameter for the formation of new particles. We calculated ratios of UVA to different solar bands (PAR - photo synthetically active radiation, reflected PAR, global, reflected global and net radiation) and plotted these ratios against the number concentrations of particles between $3-5 \mathrm{~nm}$ during the time the particle bursts occurred. Our analysis for that work was based on radiation sensor data from 1999. In January 2000 we installed a radiospectrometer - measuring solar irradiance between 280 $580 \mathrm{~nm}$ - in Hyytiälä and in this experimental series we used continuous measurements made with this instrument to investigate more detailed information about what part of the solar spectrum has the highest influence on the formation of newly formed aerosols.

\section{Measurements}

Data were collected at the Station for Measuring Forest Ecosystem-Atmosphere Relations (SMEAR II) in Hyytiälä, Finland. The station is located in Southern Finland $\left(61^{\circ} 51^{\prime} \mathrm{N}, 24^{\circ} 17^{\prime} \mathrm{E}, 181 \mathrm{~m}\right.$ asl), within extended areas of pine-dominated forests. For a detailed description of the SMEAR II station and instrumentation, we refer to Vesala (1998). The conditions at the site are typical for a background location, however, occasionally measurements were polluted by the station buildings $(0.5 \mathrm{~km})$ and the city of Tampere $(60 \mathrm{~km})$ both located in a west-south-west direction from the instruments.

Nucleation events have been classified into A, B and C classes (Mäkelä et al., 2000) and an extra group (marked by S) for days with small indications that the formation of new particles had occurred but not enough indications to classify the formation as an event. Class A events are categorised by high amounts of $3 \mathrm{~nm}$ particles and continuous growth to larger particle sizes. Class B events show the same behaviour with less clarity and class $C$ events are marginal nucleation events where one of the two stages was not clearly observed.
This type of classification is quite subjective and takes into account the uncertainties and limitations of the instrumentation. Because of this, there will always exist an overlap between the classes. There are new numerical methods which have been published (Birmili et al., 2001) to classify different event days by the maximal number concentration of particles in the nucleation mode, the background aerosol concentration and the characteristic times for the concentration curves of the newly formed particles increase and decrease.

These methods may have some advantages compared to our technique of looking at all the days and deciding in a more or less subjective way the class of the event. However there are still disagreements in the scientific community about the best way numerical solutions can be used for classification and all numerical methods need to be modulated to the location. For these reasons we used for this work the old classification system for the events. In Table 1 all events of 2000 and 2001 are listed including the start and the end time of the particle bursts and some extra parameters which will be explained later. The monthly distribution of A to $\mathrm{C}$ events for 2000 and 2001 (Fig. 1) shows two peaks: the first one in spring (March till May) with $40 \%$ of event-days and a second smaller one in autumn (August and September) with 25\% of the events.

The spectral solar radiation data were measured using a radiospectrometer system produced by Bentham (England). The system consists of the following four components:

- A DM150 double monochromator with $300 \mathrm{~mm}$ focal length, fixed slit, remote operated swing-away mirror, holographic gratings ( $2400 \mathrm{~g} / \mathrm{mm}$ blazed at 250$)$, internal 6-position stepping-motor-driven filter wheel, filter set for UV solar measurement (selected for order sorting and optimum stray light detector hysteresis) and an end window pmt bialkali photo cathode

- Benthams 200 series Detection electronics; including the 217-T power supply \& display, 215 high voltage power supply, 228A integrating A to D converter and 267 programmable d.c. amplifier

- Input optics; including a ptfe diffuser (200-800 nm) and an UV transmitting fibre optic $(2 \mathrm{~m}, 4 \mathrm{~mm}$ dia to $13 \times$ $1 \mathrm{~mm})$

- Data transfer equipment; including a 488/IEEE interface card for use with a PCMIA expansion socket on a PC, two IEEE/488 Cables, radiospectrometer control and data acquisition, display and manipulation software

The whole system is placed above the tree level in a small wooden cottage on a $10 \mathrm{~m}$ high building to insure an undisturbed solar irradiance throughout the year. The diffuser is protected by a quartz-glass which has a high transmittance (94-96\%) in the measured wavelength-range and dry air is streaming permanently into the dome to prevent condensation. The calibration of the glass dome is made by measuring 
Table 1. Date, start and end time of the particle bursts; Time of the day spectral irradiance (300-339 nm) reaches $600 \mathrm{~mW} \mathrm{~m}^{-2}$; Time of the day particle concentration (3-10 nm) exceeds 400 particle $\mathrm{cm}^{-3}$; Maximal spectral irradiance (in 300-339 nm) and maxima particle number concentration (in 3-10 nm) for all A- and B-events of 2000 and 2001

\begin{tabular}{|c|c|c|c|c|c|c|c|}
\hline Date & Doy & $\begin{array}{l}\text { Start of } \\
\text { particle }\end{array}$ & $\begin{array}{l}\text { End of } \\
\text { burst }\end{array}$ & Time at $I_{600}$ & $\begin{array}{c}I_{\max }\left[\mathrm{mW} \mathrm{m}^{-2}\right] \\
(300-339 \mathrm{~nm})\end{array}$ & Time at $N_{400}$ & $\begin{array}{c}N_{\max }\left[\mathrm{cm}^{-3}\right] \\
(3-10 \mathrm{~nm})\end{array}$ \\
\hline \multicolumn{8}{|c|}{ A-Events } \\
\hline 20000205 & 36 & 9,18 & 15,41 & 11,74 & 628 & 9,51 & 2073 \\
\hline 20000311 & 71 & 9,49 & 14,95 & 7,78 & 4249 & 10,38 & 2542 \\
\hline 20000312 & 72 & 11,21 & 16,69 & & & 11,21 & 3272 \\
\hline 20000329 & 89 & 8,69 & 15,44 & 6,84 & 5967 & 8,43 & 10848 \\
\hline 20000407 & 98 & 8,39 & 14,79 & 6,47 & 6066 & 9,08 & 2029 \\
\hline 20000502 & 123 & 10,78 & 14,79 & 5,40 & 7975 & 10,84 & 4026 \\
\hline 20000504 & 125 & 6,95 & 14,39 & 5,36 & 8330 & 7,10 & 2885 \\
\hline 20000506 & 127 & 6,27 & 15,01 & 5,18 & 8520 & 5,89 & 3976 \\
\hline 20000507 & 128 & 9,61 & 15,56 & 5,09 & 8236 & 9,65 & 3699 \\
\hline 20000508 & 129 & 9,00 & 13,47 & 5,29 & 7347 & 9,37 & 2433 \\
\hline 20000511 & 132 & 7,72 & 17,94 & 5,50 & 7898 & 8,62 & 2415 \\
\hline 20000512 & 133 & 6,92 & 17,92 & & & 7,25 & 8086 \\
\hline 20000514 & 135 & 9,86 & 14,82 & & & 10,41 & 1469 \\
\hline 20000515 & 136 & 11,36 & 13,17 & & 9051 & 11,47 & 1901 \\
\hline 20000518 & 139 & 7,90 & 13,90 & 4,85 & 8318 & 7,66 & 4126 \\
\hline 20000921 & 265 & 10,90 & 14,85 & & & 11,32 & 6482 \\
\hline 20000926 & 270 & 11,36 & 15,65 & & & 11,61 & 1884 \\
\hline 20010216 & 47 & 10,96 & 15,10 & 9,28 & 2128 & 11,33 & 2743 \\
\hline 20010307 & 66 & 10,78 & 15,16 & & & 9,64 & 3846 \\
\hline 20010319 & 78 & 9,80 & 16,93 & 7,50 & 4422 & 10,03 & 7592 \\
\hline 20010325 & 84 & 10,26 & 15,34 & 7,17 & 5004 & 10,49 & 2792 \\
\hline 20010403 & 93 & 8,27 & 13,60 & 6,64 & 6057 & 8,35 & 4859 \\
\hline 20010405 & 95 & 8,85 & 12,25 & 6,69 & 4939 & & 3320 \\
\hline 20010413 & 103 & 8,21 & 18,34 & & & 8,47 & 8453 \\
\hline 20010414 & 104 & 7,32 & 13,26 & & & 4,96 & 4128 \\
\hline 20010510 & 130 & 8,24 & 13,81 & 5,06 & 7478 & & 2712 \\
\hline 20010511 & 131 & 9,16 & 14,24 & 5,07 & 8975 & 9,49 & 2412 \\
\hline 20010514 & 134 & 10,47 & 14,39 & 4,94 & 8414 & 10,58 & 1375 \\
\hline 20010828 & 240 & 8,70 & 11,61 & 6,17 & 7049 & 9,01 & 4056 \\
\hline 20000117 & 17 & 12,40 & 16,29 & & & 12,86 & 1303 \\
\hline 20000328 & 88 & 10,41 & 15,50 & 6,91 & 5440 & 10,30 & 2195 \\
\hline 20000402 & 93 & 11,27 & 16,26 & 6,67 & 6014 & 12,00 & 1995 \\
\hline 20000423 & 114 & 9,43 & 13,47 & 5,79 & 7114 & 9,46 & 2261 \\
\hline 20000427 & 118 & 13,05 & 14,36 & 5,75 & 6693 & 12,79 & 1736 \\
\hline 20000430 & 121 & 9,09 & 15,34 & 5,43 & 8043 & 9,26 & 3174 \\
\hline 20000501 & 122 & 8,50 & 15,66 & 5,37 & 7917 & 10,80 & 1149 \\
\hline 20000505 & 126 & 9,83 & 13,54 & 5,44 & 7979 & 10,17 & 1803 \\
\hline 20000516 & 137 & 7,74 & 12,43 & 4,84 & 9109 & & 1285 \\
\hline
\end{tabular}

solar radiation on cloudless days with and without the glass about twice per year.

The calibration sources include two calibrated Bentham CL6-H lamps $(150 \mathrm{~W}, 250-2500 \mathrm{~nm}$, in a housing with mounting for a direct connection to diffuser), a current stabilised power supply $250 \mathrm{~W}$ with automatic current ramp up/down facility and a mercury calibration lamp with a mounting for direct connection to the DM150. The signal calibration is carried out once a month with one of the two CL6-H lamps and once every 3 months the second CL6-H lamp is used as a reference emitter to recalibrate the first lamp if necessary. The wavelengths are checked also once every three months and in the two years a maximum wavelength shift of $0.4 \mathrm{~nm}$ at $253.65 \mathrm{~nm}$ was detectable.

The spectroradiometer has been making measurements every 30 minutes since 28 January 2000 . The scans are from 
Table 1. Continued ...

\begin{tabular}{|c|c|c|c|c|c|c|c|}
\hline Date & Doy & $\begin{array}{l}\text { Start of } \\
\text { particle }\end{array}$ & $\begin{array}{l}\text { End of } \\
\text { burst }\end{array}$ & $\begin{array}{l}\text { Time at } I_{600} \\
(300-339 \mathrm{~nm})\end{array}$ & $I_{\max }\left[\mathrm{mW} \mathrm{m}^{-2}\right]$ & $\begin{array}{l}\text { Time at } N_{400} \\
\quad(3-10 \mathrm{~nm})\end{array}$ & $N_{\max }\left[\mathrm{cm}^{-3}\right]$ \\
\hline \multicolumn{8}{|c|}{ B-Events } \\
\hline 20000527 & 148 & 9,46 & 16,60 & 4,60 & 9498 & 9,61 & 1339 \\
\hline 20000605 & 157 & 7,25 & 10,44 & & & 8,02 & 753 \\
\hline 20000610 & 162 & 9,97 & 13,49 & 4,36 & 9844 & 11,00 & 986 \\
\hline 20000611 & 163 & 8,50 & 11,38 & 4,49 & 8646 & 9,51 & 884 \\
\hline 20000613 & 165 & 8,36 & 12,03 & 4,28 & 9645 & 8,39 & 1069 \\
\hline 20000614 & 166 & 9,61 & 15,44 & & 9907 & 9,91 & 1884 \\
\hline 20000615 & 167 & 7,29 & 14,55 & 4,30 & 10947 & 8,03 & 1748 \\
\hline 20000617 & 169 & 9,55 & 15,07 & 4,14 & 9842 & 10,05 & 1734 \\
\hline 20000621 & 173 & 7,68 & 12,71 & 4,27 & 9632 & 8,15 & 1217 \\
\hline 20000710 & 192 & 9,64 & 11,67 & & & 10,41 & 447 \\
\hline 20000727 & 209 & 8,42 & 14,52 & 4,95 & 9475 & 8,95 & 2827 \\
\hline 20000728 & 210 & 11,15 & 11,97 & 5,29 & 5340 & 11,56 & 437 \\
\hline 20000816 & 229 & 10,04 & 12,16 & 6,20 & 7793 & 10,60 & 614 \\
\hline 20000827 & 240 & 10,10 & 14,92 & & 6163 & 10,79 & 2255 \\
\hline 20000906 & 250 & 10,81 & 13,38 & & 3838 & 10,74 & 1538 \\
\hline 20000907 & 251 & 10,38 & 15,10 & 6,57 & 5788 & 10,82 & 4196 \\
\hline 20000910 & 254 & 13,05 & 16,51 & 6,93 & 4767 & 13,21 & 2044 \\
\hline 20000915 & 259 & 9,46 & 15,53 & 6,90 & 5522 & 9,71 & 1488 \\
\hline 20000916 & 260 & 11,18 & 13,11 & 6,92 & 5239 & 11,60 & 627 \\
\hline 20000919 & 263 & 12,53 & 15,65 & & & 12,58 & 3358 \\
\hline 20010220 & 51 & 9,07 & 15,49 & 9,07 & 2304 & 9,73 & 1511 \\
\hline 20010308 & 67 & 10,96 & 16,87 & & 3718 & 12,64 & 2121 \\
\hline 20010317 & 76 & 9,04 & 17,27 & 7,64 & 4203 & 8,94 & 2398 \\
\hline 20010318 & 77 & 9,86 & 16,01 & 7,64 & 3679 & 11,89 & 1432 \\
\hline 20010503 & 123 & 9,77 & 17,70 & 5,30 & 8070 & & 9139 \\
\hline 20010506 & 126 & 9,65 & 17,54 & 5,24 & 8287 & 10,64 & 1491 \\
\hline 20010513 & 133 & 8,06 & 12,65 & 5,05 & 8272 & 7,81 & 7531 \\
\hline 20010516 & 136 & 9,71 & 16,20 & 4,91 & 8432 & 11,06 & 1282 \\
\hline 20010526 & 146 & 9,92 & 13,04 & & & 10,75 & 741 \\
\hline 20010802 & 214 & 7,54 & 14,45 & 5,21 & 9221 & & 1276 \\
\hline 20010819 & 231 & 9,37 & 14,79 & 5,84 & 7542 & 7,46 & 1075 \\
\hline 20010927 & 270 & 9,98 & 14,73 & 7,39 & 4766 & 9,41 & 1900 \\
\hline 20010928 & 271 & 13,29 & 17,39 & 7,90 & 3551 & 14,08 & 2390 \\
\hline 20010929 & 272 & 9,86 & 17,08 & & & 10,27 & 1012 \\
\hline 20010930 & 273 & 10,08 & 16,32 & & & 9,82 & 2787 \\
\hline 20011019 & 292 & 13,26 & 16,69 & 8,89 & 2293 & 13,41 & 1632 \\
\hline
\end{tabular}

$280-580 \mathrm{~nm}$ and the step-width is $1 \mathrm{~nm}$. The row data are stored and recalibrated afterwards to enable later corrections of the data if necessary.

A Differential Mobility Particle Sizer (DMPS) system (located near the mast) monitors aerosol size distributions at a height of $2 \mathrm{~m}$ from ground level giving a continuous view of the distribution and evolution of sub-micrometer aerosol particles. The DMPS system used here actually consists of two components. The first one includes a TSI 3025 UFCPC and a Hauke-type short DMA (Differential Mobility Analyzer) and measures particles between 3 and $20 \mathrm{~nm}$ in dry diameter. The second includes a TSI 3010 CPC and a Hauke- type medium DMA capable of measuring particles between 20 and $500 \mathrm{~nm}$. Particle size distribution is recorded every 10 min. A detailed description of this system is given in Jokinen and Mäkelä (1997) and Mäkelä et al. (1997).

Concentrations of ozone were measured with a TEI 49 (Thermo Environmental Instruments) gas analyser based on $\mathrm{O}_{3}$ specific absorption of UV light. Air samples were collected from the mast at heights of $4.2 \mathrm{~m}, 16.8 \mathrm{~m}$ and $67.2 \mathrm{~m}$ every $5 \mathrm{~min}$. Temperature (measured with PT-100-sensors) were collected every $50 \mathrm{~s}$ at these three heights as well. 


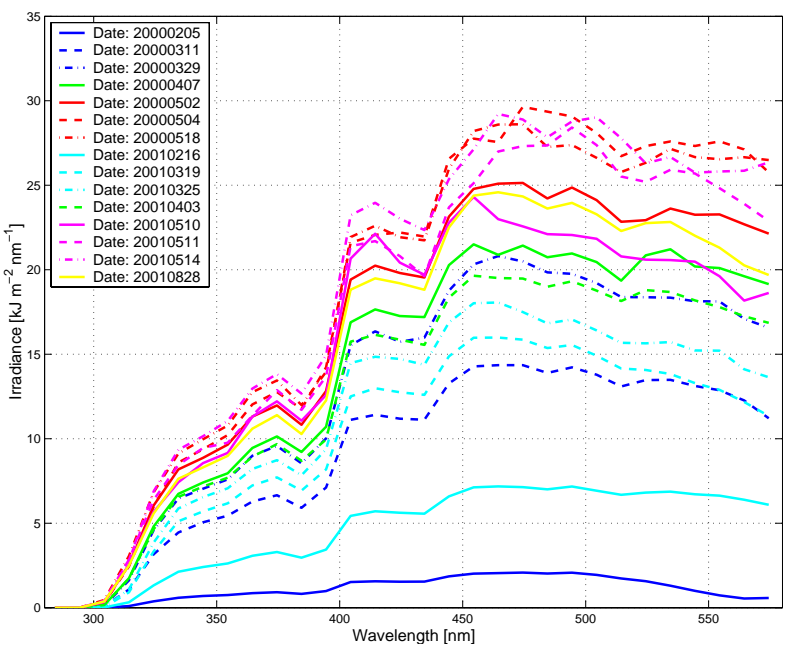

Fig. 2. Spectral solar irradiance for a representative selection of A-event days in 2000 and 2001.

\section{Correlation between nucleation and solar spectral ir- radiance}

\subsection{Concerning the classification of the events}

The importance of solar irradiance for the formation of new particles and the growth of these particles to the Aitken mode has been described in many papers (Birmili and Wiedensohler, 2000; Clement et al., 2000; Kulmala et al., 2001a). However, it is still an open question as to what part of the solar spectrum is responsible for the realization of these processes. To date, nearly all publications have used measurements of global solar irradiance as the radiation parameter. In this work we analysed data from a radiospectrometer measuring solar radiation from 280 to $580 \mathrm{~nm}$ with a step width of one nm to gain detailed information about which wavelength range of the solar spectrum has more influence on the formation of new aerosols.

In the first step we divide the measured spectral solar irradiance ISPR into 30 groups with $10 \mathrm{~nm}$ wavelength ranges and calculate the average solar irradiance per group per scan per nanometer by

$I_{S, G}(j, h, d)=\frac{1}{10} \sum_{k=s w(j)}^{e w(j)} I_{S P R}(k, h, d)$

with

$s w(j)=[280,290,300, \ldots, 570] \mathrm{nm}$

$e w(j)=[289,299,309, \ldots, 579] \mathrm{nm}$

$j$ is the number of the wavelength groups from 280 to $580 \mathrm{~nm}, h$ is the time of the scans starting at 00:00 ending at 23:30 LT (every half hour) and $d$ is the day of the year going form 1 to 731 for 2000 and 2001.
According to our own experience gained from analysing data for two years and the results of Mäkelä et al. (2000) nearly all of the particle bursts occurred between 08:00 and 16:00 LT (see also Table 1). For these reasons in Eq. (2) we calculate the solar energy $E_{G}$ for each wavelength group and day during this time period.

$E_{G}(j, d)=\sum_{h=17}^{32}\left(I_{S, G}(j, h, d) \cdot 1800\right)$

Figure 2 shows the $E_{G}$ curves for 15 A-Events in 2000 and 2001 (monthly representative selection). The curves show the same trend but there is a difference of more than one magnitude in all wavelength groups between the highest solar irradiance on 18 May 2000 and 5 February 2000. Although we can produce these plots for all event and non-event days for the two years, the plots will not give us differences in the spectral distribution for different days. Therefore we normalise every day by dividing all wavelengths groups by the mean value of this day between 330 and $380 \mathrm{~nm}$. We then obtain $A v$, the average of this wavelengths interval, and can then calculate a normalised solar energy $E N_{G}$ for every day and wavelength group:

$$
\begin{aligned}
& A v(j, d)=\frac{1}{5} \sum_{j=6}^{10} E_{G}(j, d) \\
& E N_{G}(j, d)=\frac{E_{G}(j, d)}{A v(j, d)}
\end{aligned}
$$

The reasons we choose the 330 to $380 \mathrm{~nm}$ wavelength interval is the nearly linear trend with different slopes for all these curves throughout the year and the fact that irradiance in this range is mostly diminished by the scattering of permanent gases in the atmosphere and not by water vapour (Seinfeld and Pandis, 1998). In order to compare different event days with all days we now calculate first in Eq. (4) an average normalised spectral solar energy graph.

$\overline{E N_{G, N}(j)}=\frac{1}{N E} \sum_{d=1}^{N E} E N_{G}(j, N(d))$

with the number of all measured days $N E=546$. The graph of $\overline{E N_{G, N}}$ can now be used as a reference graph of normalised spectral distribution for all days in 2000 and 2001. Now we divide every wavelength group of the A-event days in Fig. 2 with the corresponding values from Eq. (4) by

$R_{A}(j, A(d))=\frac{E N_{G}(j, A(d))}{\overline{E N_{G, N}(j)}}$

The results of Eq. (5) are plotted for all A-events in Fig. 3. The data for wavelengths numbers smaller than $300 \mathrm{~nm}$ are uncertain since in this wavelength range we are most of the year at the detection limit of the instrumentation with values smaller than $1 \mathrm{~mW} \mathrm{~m}^{-2}$. However, we recognise on all 


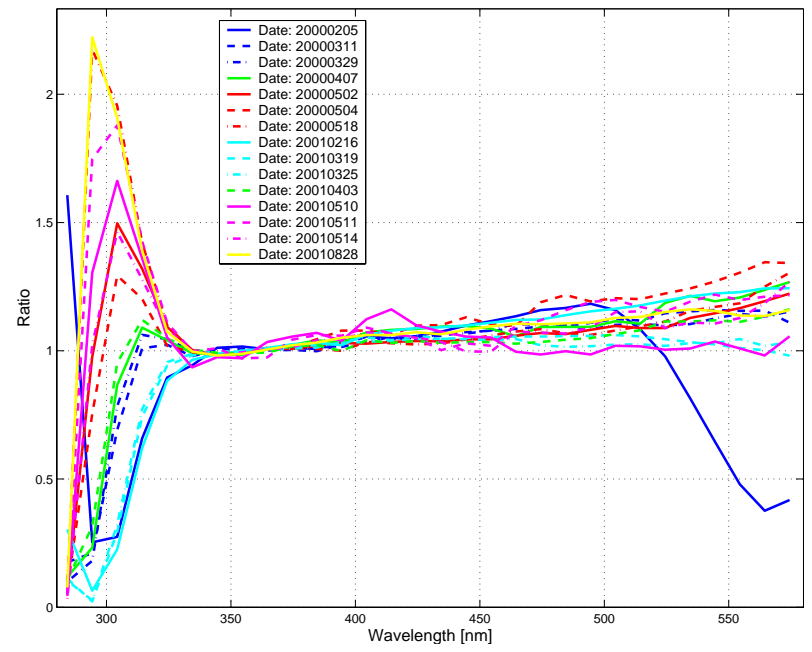

Fig. 3. Ratios for A-events from Fig. 2 of spectral solar irradiance against a yearly reference graph from Eq. (4) $\left(\overline{E_{G, N}}\right)$.

days in April until September (green, red, magenta and yellow curves) a steep rise toward smaller wavelength numbers starting between 330 and $340 \mathrm{~nm}$. This can be equated with an increase in solar radiation by a factor up to 2 . On the other side the event days in February and some of the days in March (blue curves) behave in the opposite way with a decrease of spectral irradiance at wavelengths below $340 \mathrm{~nm}$. The right hand side of all the curves are more bunched and mixed than the left side with a weak slope toward higher wavelength numbers. The rest of the A- and B-event days show a similar trend to those in Fig. 3 with a steep increase below $340 \mathrm{~nm}$ from April to September and a decrease in the same wavelength range in the autumn and winter months. The reason for this behaviour is physical. In the Finnish autumn and winter the solar zenith angle is always larger than $60^{\circ}$ and so the pathway of the solar beam through the atmosphere is much longer compared to summer or spring. Rayleigh scattering is more effective for smaller wavelength than for larger once and this has the consequence that our calculated yearly reference curve is inadequate. To avoid this we calculate by Eq. (6) equal to Eq. (4) and Eq. (5) a spectral solar reference curve for every month and the ratios for every event day to the corresponding month:

$$
\begin{aligned}
& \overline{E N_{G, N, M}(j, m)}=\frac{1}{M D(m)} \sum_{d=1}^{M D(m)} E N_{G}(j, M(d)) \\
& R_{A, M}(j, A(d, m))=\frac{E N_{G}(j, A(d))}{E N_{G, N, M}(j, m)}
\end{aligned}
$$

with $M D$ the amount of measured days per month in 2000 and 2001 (e.g. February = 57). In Fig. 4 the calculated ratios of $R_{A, M}(j, A(d, m))$ are plotted for the A-events of Fig. 2. If we compare this figure now with Fig. 3 we can see that the trend of increasing short wavelength irradiance in spring and summer has disappeared. Further we realise that both events

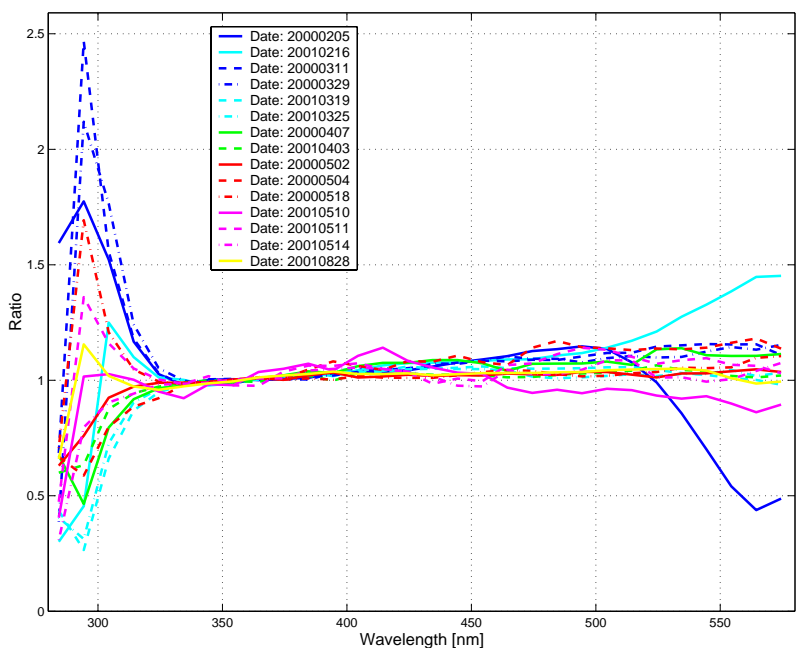

Fig. 4. Ratios for A-events from Fig. 2 of spectral solar irradiance against monthly reference graphs from Eq. (6) $\left(\overline{E_{G, N, M}}\right)$.

in February and the events in March 2000 show a steep increase in short wavelength radiation in comparison with the reference curve for the corresponding month. The highest increase is by a factor of 2 for the day in March with the smallest amount of solar irradiance (see Fig. 2). We also found that in spring and summer higher and smaller values of spectral radiation between 300 and $340 \mathrm{~nm}$ on the event days are well mixed. If we combine the results from Fig. 3 and 4 we can conclude that short wavelength irradiance between 300 and $340 \mathrm{~nm}$ is higher on most event days in winter compared to a normalised reference graph for all days of the corresponding month but quantitative still much smaller than in spring or summer. It appears that on days with a low amount of solar energy the relative high values of irradiance between 300 and $340 \mathrm{~nm}$ seem to be important. The same results presented here for some of the A-events in 2000 and 2001 can be seen for all the event days. This indicates that for the formation of new particles the responsible solar radiation band is short wavelength irradiance in UV-B and the first 10 to $20 \mathrm{~nm}$ of UV-A. We calculate now for all event classes throughout the two years a comprehensive mean value for every wavelength group according to Eq. (4) with $N E$ being now the number of measured event days per class and divide then these values by the values of our reference graph of normalised spectral irradiance for all days in 2000 and $2001\left(\overline{E N_{G, N}}\right)$. The average irradiance per class and the results of the above calculations are shown for all classes in Fig. 5. The amount of solar energy is for A-, B- and C-events in all wavelength groups about 2 times higher compared to the average for all the days in the two years and about 3 times higher compared to the non-event days. The graphs further show an increase in the short wavelength range between 300 to $340 \mathrm{~nm}$ and a continuously light increase towards higher wavelengths. 

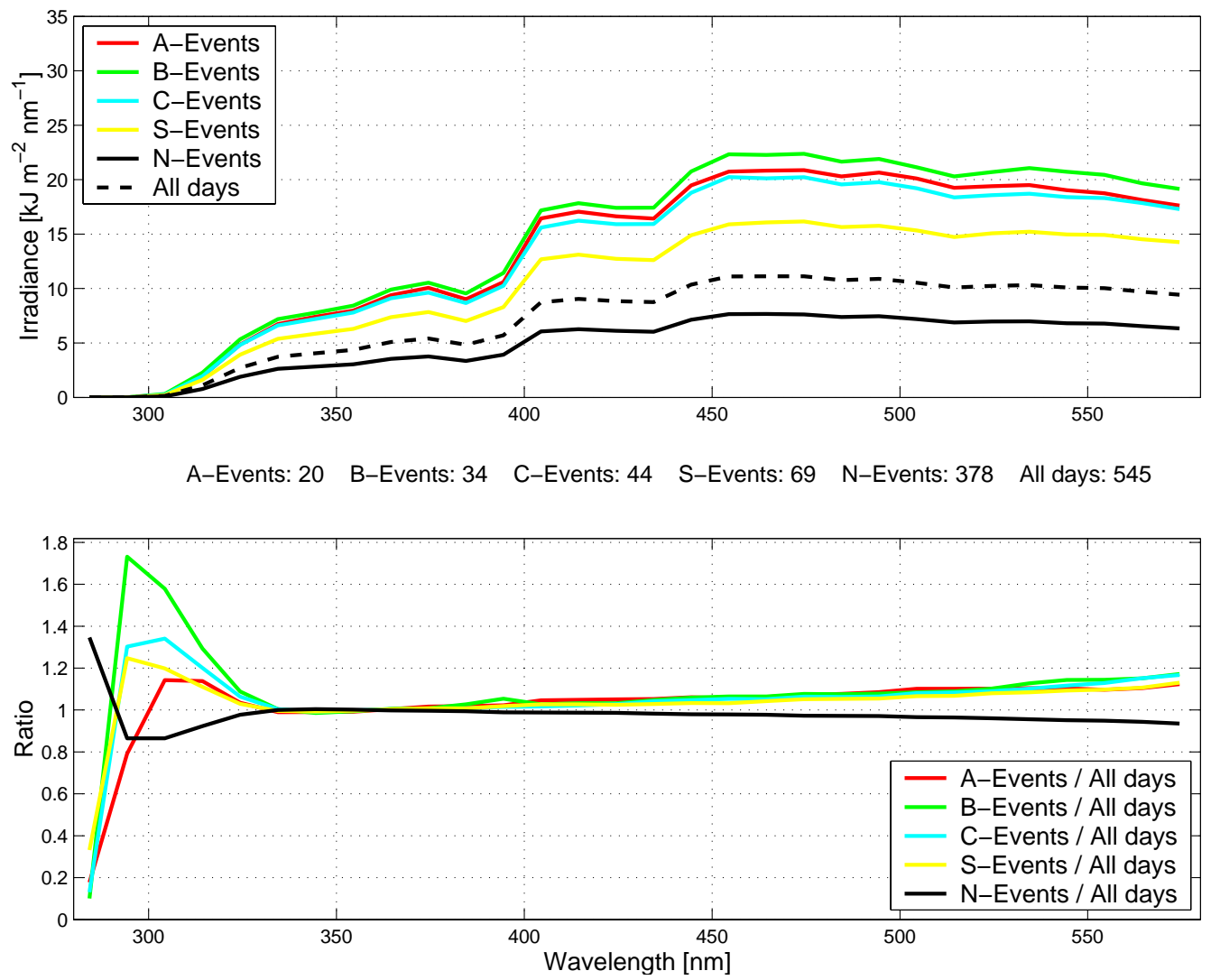

Fig. 5. (a) Average spectral solar irradiance for all event and non-event classes of 2000 and 2001; (b) Ratio of the graphs from (a) to a yearly reference graph from Eq. (4) $\left(\overline{E_{G, N}}\right)$.

\subsection{Concerning the number concentration of the particles}

So far we have only compared the spectral solar irradiance with a classification of the single days into those with events and non-events. Furthermore, we have included half hour average values of number concentrations of different particle size ranges (size ranges: $3-5 \mathrm{~nm}, 3-6 \mathrm{~nm}, 3-10 \mathrm{~nm}$ and 3$50 \mathrm{~nm})$. We have calculated correlation coefficients between the number concentration of the particles and the irradiance in the different wavelength groups for every day of the two years. The results with the highest correlations are those, which use a particle size of 3-10 nm. The differences in the correlation coefficients between the smaller size ranges and the $3-10 \mathrm{~nm}$ range is negligible $(<0.02)$. It could be due to the fact that at this small range $3-5 \mathrm{~nm}$ or $3-6 \mathrm{~nm}$ we are measuring particles at the detection limit of the DMPS system. So our results are more reliable if larger particles such as 3 to $10 \mathrm{~nm}$ were included for the following discussion. The size range 3 to $50 \mathrm{~nm}$ also includes the Aitken mode aerosols and here the correlation coefficients reach only half the previous values. This may be due to the fact that in this size range beside condensational growth, coagulation plays an important role and the influence of solar radiation is less important.

Figure 6 gives the average correlation coefficients between the number concentrations of particles between 3 and $10 \mathrm{~nm}$ and the spectral solar irradiance for the different classes in a histogram plot. The solid lines in each subplot mark the maximum value of the correlation coefficient in each class. The number of measured days per class is included in each subplot. All of the three event classes (A, B and C) have the highest correlation in the wavelength groups $3-5$, which corresponds to the short wavelength range between 300 $329 \mathrm{~nm}$. After $330 \mathrm{~nm}$ the gaps between the solid lines and the bars in the first three subplots increase slightly towards higher wavelengths and reach a maximum around $30 \%$ at $580 \mathrm{~nm}$. The absolute values of the correlation coefficients are not very high (around 0.6 for A-events) but we have to remember that these numbers are averages over all events per class and that in this context more than for the absolute values, the differences of the correlation coefficients between the single wavelength groups are interesting.

\subsection{Case study for 5 May 2002}

We will use now an example-day (5 May 2000) and present reasons for the higher correlation coefficients of the short wavelength bands. In order to do this we plotted the daily particle number concentrations for particles $(3-10 \mathrm{~nm})$, 

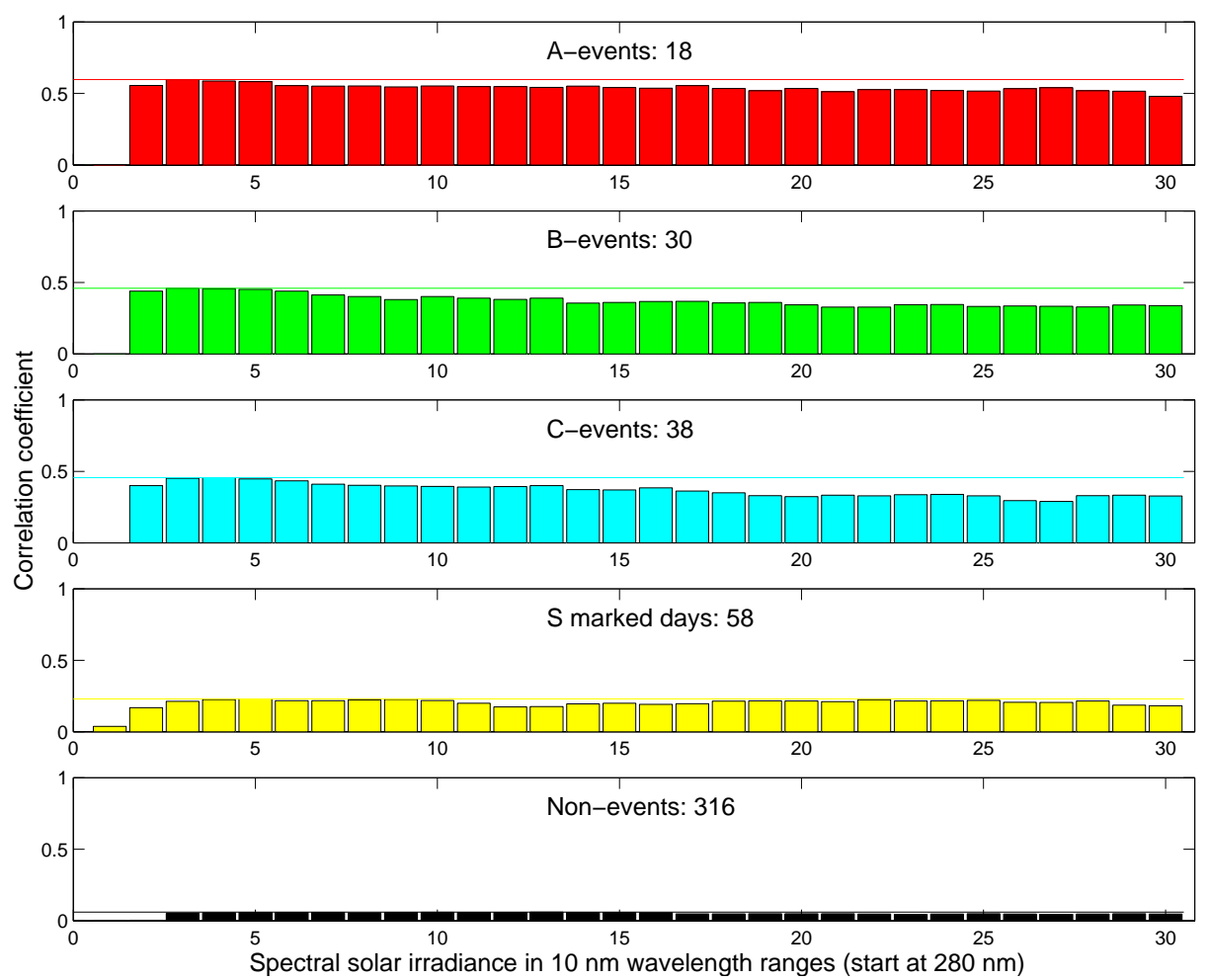

Fig. 6. Correlation coefficients for event classes between the number concentration of particles (3-10 nm) and the wavelengths groups from Eq. (1) $\left(I_{S, G}\right)$.

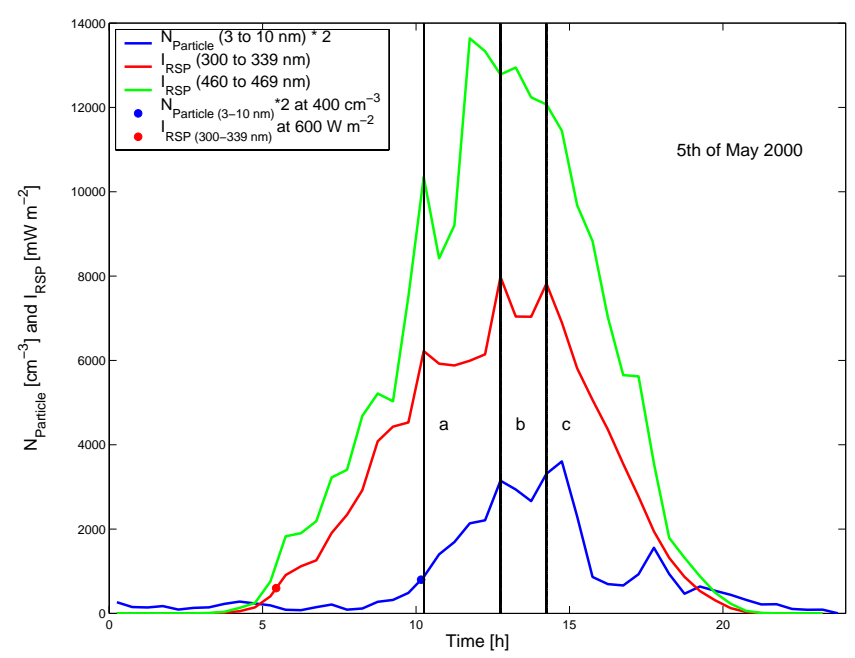

Fig. 7. Daily pattern of spectral solar irradiance and number concentration of particles for 5 May 2000.

short (300-339 nm) and longer wavelength irradiance (460$469 \mathrm{~nm}$ ) in Fig. 7. The graph firstly shows that longer wavelength irradiances start to increase earlier as shorter (green compared to red curve). This is a physically well-known effect and because particle bursts always appear after sunrise and stop mostly long before sunset (see Table 1) this leads to higher correlation coefficients between UV solar radiation and the particle number concentrations. The second reason for the higher coefficients can be explained by the three peaks in the short wavelength irradiance curve marked by black lines ( $a, b$ and $c)$. The irradiance peaks at line (a) and (c) in the morning and in the afternoon also appear in the particle curve during the next hour. The peak at line (b) around noon has no time lag and occurs at the same time in the radiation and particle concentration. Such patterns of solar radiation and particle number concentration curves occur on many event days. Most times the particles trends and peaks better fit the shorter wavelength of the solar spectrum by having the smallest time lags between peaks around noon when the pathways for the solar beam through the atmosphere reach their minima. However there are still event days where the correlation is quite small, but before making any conclusions we should consider two important facts:

- The radiospectrometer and the DMPS system are about $200 \mathrm{~m}$ apart from each other and the influence of moving clouds are not negligible for the solar irradiance at this distance.

- For both data sets (spectral irradiance and particles) half hour average values were used. A time step is necessary for handling all the data in reasonable computer time, 
however many interested features of the daily trend are neglected.

\subsection{Time lag between irradiance and particle increases}

At the end of this session we use for each parameter - short wavelength radiation and particle concentration - one selected value to calculate the time difference between the two curves. For the particle we took the time when the concentration exceeds 400 particles $\mathrm{cm}^{-3}$ (blue dot in Fig. 7) and for the irradiance we chose $600 \mathrm{~mW} \mathrm{~m}^{-2}$ (red dot in Fig. 7). The chosen values for irradiance and number concentration of particles are subjective selections for the situation in Hyytiälä, Finland and are not competitative for other locations. Figure 8 shows for all A- and B-event days for both parameters the specified times and the time lack (see also Table 1). There is a trend - especially in 2001 - that the time differences (green dots) with values around $0.5-2 \mathrm{~h}$ are smaller in winter till the beginning of spring than in summer and autumn $(2-7 \mathrm{~h})$. However, for the first event day on 5 February the particle concentration exceeds already two hours earlier the amount of 400 particles $\mathrm{cm}^{-3}$ before the irradiance reaches $600 \mathrm{~mW} \mathrm{~m}^{-2}$. A more detailed analysis of different parameters of this day showed that on 5 February the highest ozone concentrations ( $39 \mathrm{ppb}$ ) between 1 January till 11 March were measured and that the concentration of $\mathrm{H}_{2} \mathrm{O}$ was as small as $10^{17}$ molecules $\mathrm{cm}^{-3}$. Further biological activity measured by $\mathrm{CO}_{2}$ flux measurements in chambers were going on at this day. Bonn et al. (2002) investigated in laboratory experiments the highest ozonolysis-rates of monoterpenes and special of exocyclic monoterpenes $(\beta$ pinene and sabinene) for low water vapour and high ozone concentrations. Exactly this physical situation can be seen on day 36 of 2000. This feature and the results above indicate that there are most probably different chemical and photochemical mechanisms responsible for the production of the condensable vapour/s. From the high conformity between the short wavelength spectrum and the particles it appears that radiation leads to the formation of new aerosols on many event days, however, on other event days different mechanisms such as the ozonolysis of monoterpenes seem to be more important.

\section{A potential mechanism explaining the indirect influ- ence of short wavelength irradiance on the formation of SOA}

In the previous session we showed that the short wavelengths range between 300 and 330 or $340 \mathrm{~nm}$ seems to be the most important spectral solar radiation band concerning the formation of new particles or the growth of new clusters to the detectable $3 \mathrm{~nm}$ size. In this session we will continue with this result and present a photochemical reaction mechanisms, as a hypothesis explaining the possible indirect influence of short

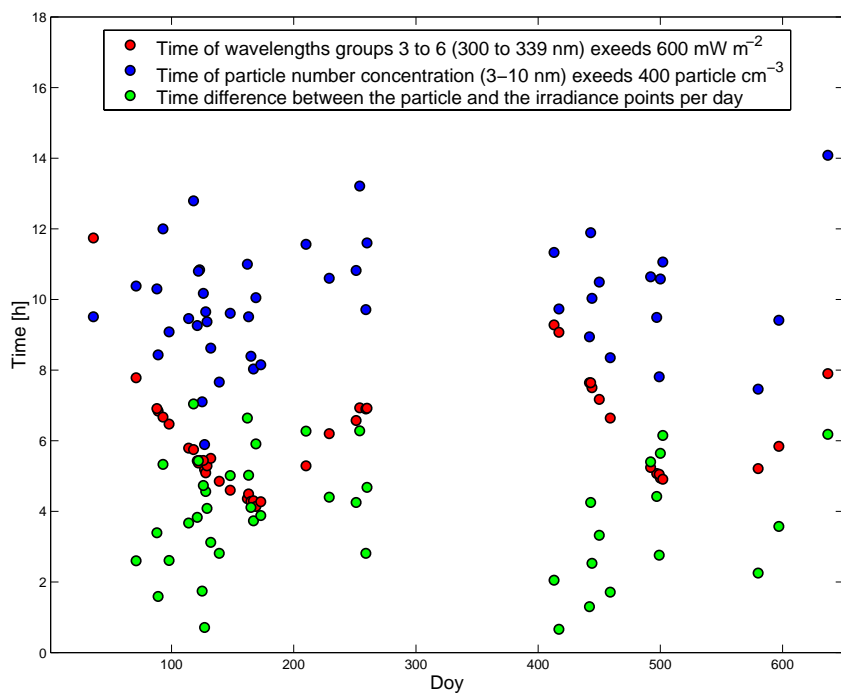

Fig. 8. Time short wavelength irradiance $(300-339 \mathrm{~nm})$ exceeds $600 \mathrm{~mW} \mathrm{~m}^{-2}$ and particle number concentration (3-10 nm) exceeds 400 particle $\mathrm{cm}^{-3}$ for A- and B-events of 2000 and 2001. Further the difference between the two explained time points are included.

wavelength irradiance on the production of newly formed SOA. This is only one out of possible many different mechanisms participating in the formation of aerosols and the reason for presenting it here was to show one way besides any other photochemical reactions or the onset of vertical fluxes how solar irradiance and specially short wavelength irradiance can influence the formation of SOA.

First we calculate with the radiospectrometer data (average values of $5 \mathrm{~nm}$ ranges) between 280 and $350 \mathrm{~nm}$ for every half hour and day the average number of photons per $5 \mathrm{~nm}$ intervals.

$P h o(k, h, j)=\frac{I_{S P R}(k, h, j) * W L(k)}{h *\left(c_{o}\right)}$

with $W L(k)$ the wavelength per group $(=282.5,287.5, \ldots$, $347.5 \mathrm{~nm}), h$ the Planck constant and $c_{o}$ the speed of light in a vacuum. Further we include half hour average data for ozone and temperature in our analyses and calculate with the absorption cross section ( $\mathrm{ACS}_{\mathrm{O} 3}$ - Molina and Molina, 1986) and the quantum yield (QO3 - JPL publication 00-003, 2000) of ozone the photolyse rate for $\mathrm{O}_{3}$ at the same times as in Eq. (7).

$P R_{O 3}(k, h, j)=P h o(k, h, j) \cdot Q_{O 3}(k, T) \cdot A C S_{O 3}(k)$

With the photolyse rate and the half hour average values of ozone we now calculate in Eq. (9) the production rate of $\mathrm{O}\left({ }^{1} \mathrm{D}\right)$ as a function of time and wavelength

$\mathrm{O}\left({ }^{1} \mathrm{D}\right)(k, h, j)=P R_{O 3}(k, h, j) \cdot \mathrm{O}_{3}(h, j)$

Figure 8 shows as an example the production rate of $\mathrm{O}\left({ }^{1} \mathrm{D}\right)$ for 15 May 2000. In the $x$-axis a maximum occurs around 


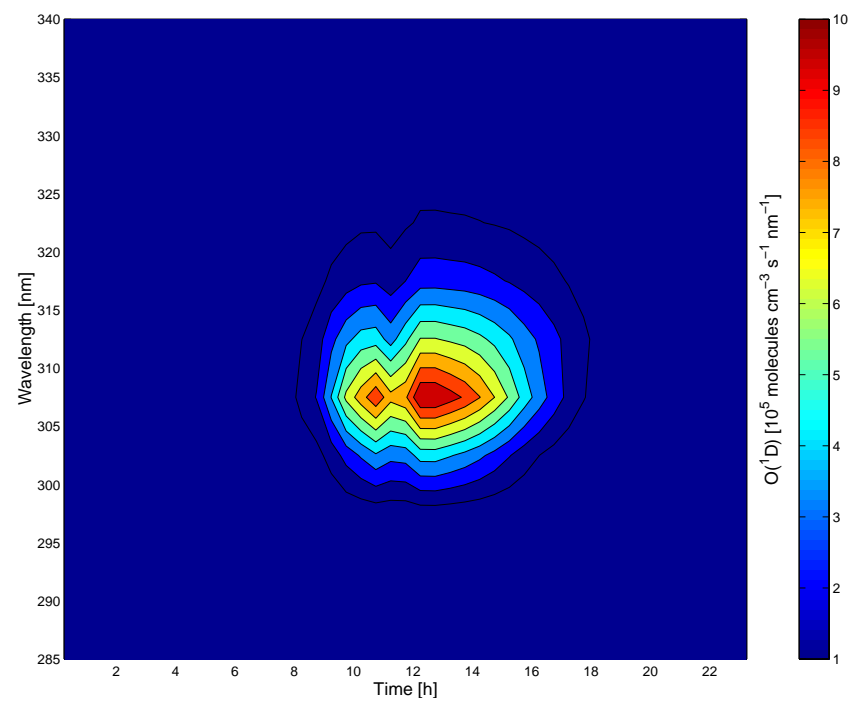

Fig. 9. Production rate of excited oxygen for 28 May 2000.

noon when the solar zenith angle has its minimum and in the $y$-axis a maximum occurs around $310 \mathrm{~nm}$ with a gradient of one magnitude in less than $15 \mathrm{~nm}$ in both directions. The maximum in the $y$-axis is a combination between the decreasing of the absorption cross-section and the quantum yield of ozone with higher wavelengths on one side and the steep increase of the spectral irradiance in the same direction on the other side. Although the absolute values of solar irradiance in the wavelength range from $300-330 \mathrm{~nm}$ is one to two magnitudes smaller than the maximum values between $450-500 \mathrm{~nm}$ this spectral solar band is the only one which enables the production of excited oxygen radicals in the troposphere. The produced $\mathrm{O}\left({ }^{1} \mathrm{D}\right)$ most often collides with $\mathrm{N}_{2}$ and $\mathrm{O}_{2}$, removing its excess energy and quenching back to its ground state by

$\mathrm{O}\left({ }^{1} \mathrm{D}\right)+\mathrm{M} \rightarrow \mathrm{O}+\mathrm{M}$

Then the oxygen atom reacts with $\mathrm{O}_{2}$ to replenish $\mathrm{O}_{3}$. Occasionally, as much as every tenth $\mathrm{O}\left({ }^{1} \mathrm{D}\right)$ radical collides with $\mathrm{H}_{2} \mathrm{O}$ and produces two hydroxyl radicals,

$\mathrm{O}\left({ }^{1} \mathrm{D}\right)+\mathrm{H}_{2} \mathrm{O} \rightarrow 2 \mathrm{OH}$

Two $\mathrm{OH}$ radicals are formed in Eq. (11) and this leads to an $\mathrm{OH}$ yield of approximately 0.2 molecule $\mathrm{OH}$ per $\mathrm{O}_{3}$ molecule photolysed at a relative humidity of $50 \%$ and a temperature of 298 K (Seinfeld and Pandis, 1998). Hydroxyl radicals do not react with the major constituents of the atmosphere $\left(\mathrm{N}_{2}, \mathrm{O}_{2}, \mathrm{CO}_{2}\right.$ and $\left.\mathrm{H}_{2} \mathrm{O}\right)$. It is still an open question, which species and what kind of chemical reactions are responsible for the production of the condensable vapours involved in the formation of new aerosols. However, there is a high possibility that excited oxygen atoms and hydroxyl radicals are involved in these reactions. We will close this session with a temporally more comprehensive view on the explored

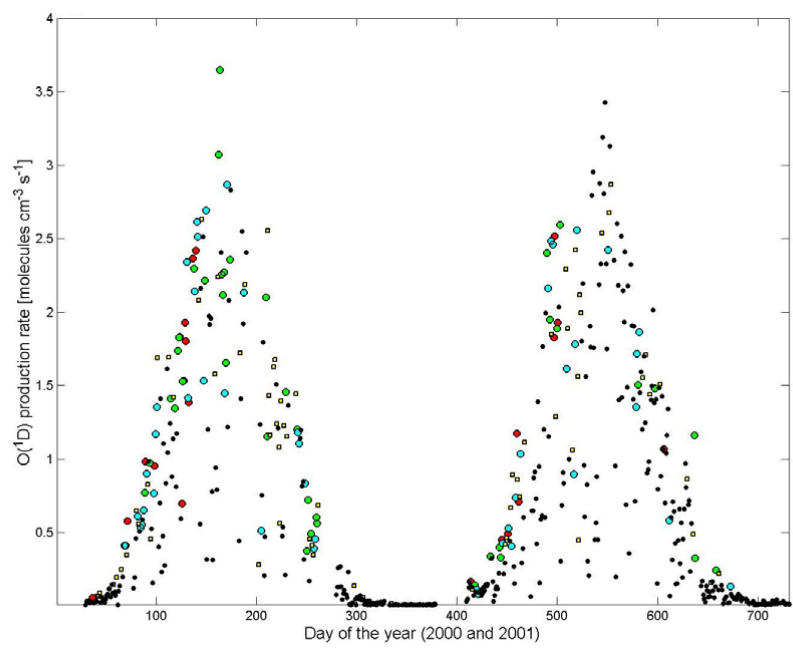

Fig. 10. Daily maxima production rate of excited oxygen for 2000 and 2001 .

theory by calculating the maxima of $\mathrm{O}\left({ }^{1} \mathrm{D}\right)$ production per day and plot these data for the whole year in Fig. 9. Most of the event days and especially the events in winter show very high values for excited oxygen production rate compared to the none-event days in the same month. However, there are still many none-event days with high values for this parameter; but it is well known that besides radiation other variables like the condensational sink, the temperature and the concentration of some till now unknown precursor species also influence the formation process of new aerosols.

\section{Summary and conclusions}

We analysed two years of solar spectral irradiance data and number concentrations of particles in different size ranges. It has been showed for the classification in events and nonevents that there exists an increase in short wavelength solar radiation on event days. By normalising all daily average spectral radiation curves with the mean value of $330-380 \mathrm{~nm}$, calculating ratios between the normalised values of events to the reference curve for all days of the two years or to reference curves for all days of the corresponding month respectively, we obtained the following results: The short wavelength irradiance between 300 and $340 \mathrm{~nm}$ on many event days in autumn and winter shows an increase compared to the reference curve for the corresponding month. During the rest of the year this trend disappears, however the absolute amounts of solar irradiance in this range is still as much as one magnitude higher in spring and summer. Using the same normalised values as before and calculating the ratios of the average of the different event classes to the reference curve of the two years we found a peak between 1.17 and 1.6 in the short wavelength range for all classes (Fig. 5) and a weak continuous increase towards higher wavelengths. 
Furthermore we calculated for every day the correlation coefficients between number concentrations of particles (3$10 \mathrm{~nm}$ ) and the different wavelengths groups. The graphs showed the same results as above with the highest correlation for the short wavelength range being between 300 and $330 \mathrm{~nm}$. A more specific answer to the reasons for the differences in the correlation coefficients was given by using an example day (5 May 2000). Plotting the curves for particle number concentration and the spectral irradiance for short (300-339 nm) and longer (460-469 nm) wavelengths brought two aspects into focus. First, a temporal later increases of shorter wavelengths and second a higher agreement on most event days between the peaks of the particle curves and the peaks of the short wavelengths groups. The first effect is a well known physically aspect and it is attributed to the fact that particle bursts always occur after the sunrise and vanish long before sunset. The second point indeed more indicates a direct influence of the short wavelength solar spectrum on the formation of newly formed aerosols. Further we plotted the time differences when the solar radiation $(300-339 \mathrm{~nm})$ exceeds a value of $600 \mathrm{~mW}$ $\mathrm{m}^{-2}$ and the particle number concentration increases to 400 particles $\mathrm{cm}^{-3}$. The results showed smaller time lags in winter and spring compared to summer and autumn with one day 5 February where the particle number concentration exceeded the selected value already two hours earlier than the irradiance. However this day also had the highest ozone concentration during winter (39 ppb), a very low amount of water vapour $\left(<10^{17}\right.$ molecules $\left.\mathrm{cm}^{-3}\right)$ and biological activities. Bonn et al. (2002) found in laboratory experiments that ozonolysis of monoterpenes had the highest rates at small concentrations of $\mathrm{H}_{2} \mathrm{O}$ and high concentrations of ozone. All conditions were present on 5 February. This indicates that during special periods different chemical and photochemical mechanisms are responsible for the production of condensable vapours and so for the formation of new aerosols.

In session 4 we presented a hypothesis to explain how the evaluated part of solar irradiance affects the production of condensable vapours and so the formation of new aerosols. For this reason we used half hour average values of ozone and temperature to calculate the production rate of excited oxygen atoms. The results of this analysis showed a maxima of $\mathrm{O}\left({ }^{1} \mathrm{D}\right)$ around noon and at $310 \mathrm{~nm}$ with a decrease of more than one magnitude below or above 295 and $325 \mathrm{~nm}$, respectively. $\mathrm{O}\left({ }^{1} \mathrm{D}\right)$ is the main source in the troposphere for the production of hydroxyl radicals and the above introduced part of the solar spectrum is the only way to produce excited oxygen atoms in the troposphere. OH radicals are the most reactive species in the troposphere steering many atmospheric chemical reactions and could also be involved in the formation of new particles through chemical reactions, which produce the condensable vapours.

We conclude this publication with a correction concerning our last paper (Boy and Kulmala, 2002). As mentioned in the introduction we suggested in that paper UV-A to be the responsible solar radiation parameter for the formation of new aerosols by using a data set of different radiation sensors for 1999. Comparing the UV sensors data of 2000 and 2001 with the calculated UV radiospectrometer data we realised that UV-A measurements of the sensor were continuously approximately $10 \%$ too high and UV-B showed a strong dependency on the solar zenith angle. It is not possible afterwards to find the reasons for the overestimation of UVA by the sensor, however a possible explanation could be the expanding of the sensor-filter (normally from 320-400 nm) into the UV-B range. This would explain the higher amounts of UV-A compared to other solar measurements during the time of the particle bursts, which occurred in 1999 and agree completely with the results of the present work.

\section{References}

Birmili, W., Berresheim, H., Plass-Duelmer, C., Elste, T., Gilge, S., Wiedensohler, A., and Uhrner, U.: The Hohenpeissenberg Aerosol Formation Experiment (HAFEX): A long-term study including size-resolved aerosol, $\mathrm{H}_{2} \mathrm{SO}_{4}, \mathrm{OH}$, and monoterpenes measurements, Atmos. Chem. Phys. Discuss., 2, 1655-1697, 2001.

Birmili, W. and Wiedensohler, A.: New particle formation in the continental boundary layer: Meteorological and gas phase parameter influence, Geophys. Res. Letts., 27, 3325-3328, 2000.

Bonn, B., Schuster, G., and Moortgat, G. K.: Influence of water vapor on the process of new particle formation during monoterpene ozonolysis, J. Phys. Chem. A, 106 (12), 2869-2881, 2002.

Boy, M. and Kulmala, K.: Nucleation events in the continental boundary layer: Influence of physical and meteorological parameters, Atmos. Chem. Phys., 2, 1-16, 2002.

Clarke, A. D.: Atmospheric nuclei in Pacific midtroposphere: Their nature, concentration and evolution, J. Geophys. Res., 98, 20 633-20 647, 1993.

Clement, C. F., Pirjola, L., Dal Maso, M., Mäkelä, J. M., and Kulmala, M.: Analysis of particle formation bursts observed in Finland, J. Aerosol. Sci., 31, 2000.

Houghton, J. T., Meira Filho, L. G., Callander, B. A., Harris, N., Kattenburg, A., and Maskell, K.: Climate change 1995, Cambridge University Press, Cambridge, 1996.

Jokinen, V. and Mäkelä, J. M.: Closed loop arrangement with critical orifice for DMA sheath/excess flow system, J. Aerosol Sci., 28, 643-648, 1997.

JPL Publication 00-003, National Aeronautics and Space Administration, 2000.

Korhonen, P., Kulmala, M., Laaksonen, A., Viisanen, Y., McGraw, R., and Seinfeld, J. H.: Ternary nucleation of $\mathrm{H}_{2} \mathrm{SO}_{4}, \mathrm{NH}_{3}$ and $\mathrm{H}_{2} \mathrm{O}$ in the atmosphere, J. Geophys. Res., 104, 26349-26353, 1999.

Kulmala, M., Dal Maso, M., Mäkelä, J. M., Pirjola, L., Väkevä, M., Aalto, P., Miikkulainen, P., Hämeri, K., and O'Dowd, C.: On the formation, growth and composition of nucleation mode particles, Tellus B, 53, 479-490, 2001a.

Kulmala, M., Hämeri, K. K., Aalto, P., Mäkelä, J., Pirjola, L., Nilsson, E. D., Buzorius, G. Rannik, Ü., Dal Maso, M., Seidl, W., Hoffmann, T., Jansson, R., Hansson, H.-C. O`Dowd, C., and 
Viisane, C.: Overview of the international project on biogenic aerosol formation in the boreal forest (BIOFOR), Tellus B, 53, 324-343, 2001b.

Kulmala, M., Pirjola, L., and Mäkelä, J. M.: Stable sulphate clusters as a source of new atmospheric particles, Nature, 404, 66-69, 2000.

Kulmala, M., Toivonen, A., Mäkelä, J. M., and Laaksonen, A.: Analysis of the growth of nucleation mode particles in Boreal Forest, Tellus, 50, 449-462, 1998.

Molina, L. T. and Molina, M. J.: Absolute absorption cross sections of ozone in the 185-350 nm wavelength range, J. Geophys. Res., 91, 14 501-14 508, 1986.

Mäkelä, J. M., Aalto, P., Jokinen, V., Pohja, T., Nissinen, A., Palmroth, S., Markkanen, T., Seitsonen, K., Lihavainen, H., and Kulmala, M.: Observations of ultrafine aerosol particle formation and growth in boreal forest, Geophys. Res. Lett., 24, 1219-1222, 1997.

Mäkelä, J. M., Dal Maso, M., Pirjola, L., Keronen, P., Laakso, L., and Kulmala, M.: Characteristics of the aerosol particle formation events observed at a boreal forest site in southern Finland, Boreal Env. Res., 5, 299-313, 2000.

Nilsson, E. D., Paatero, J., and Boy, M.: Effects of air masses and synoptic weather on aerosol formation in the continental boundary layer, Tellus, 53B, 2001.
O’Dowd, C. D., Geever, M., Hill, M. K., Smith, M. H., and Jennings, S. G.: New particle formation: Nucleation rates and spatial scales in the clean marine coastal environment, Geophys. Res. Letts., 25, 1661-1664, 1998.

Raes, F., Van Dingenen, R., Cuevas, E., Van Velthoven, P. F. J., and Prospero, J. M.: Observations of aerosols in the free troposphere and marine boundary layer of the subtropical Northeast Atlantic: Discussion of processes determining their size distribution, J. Geophys. Res., 102, 21 315-21 328, 1997.

Seinfeld, J. H.: Atmospheric Chemistry and Physics of Air Pollution, John Wiley \& Sons, New York, 1998.

Weber, R. J., McMurry, P. H., Mauldin, L., Tanner, D. J., Eisele, F. L., Brechtel, F. J., Kreidenweis, S. M., Kok, G. L., Schilawski, R. D., and Baumgardner, D.: A study of new particle formation and growth involving biogenic and trace gas species measured during ACE 1, J. Geophys. Res., 103, 16385-16396, 1998.

Weber, R. J., McMurry, P. H., Mauldin, R. L., Tanner, D., Eisele, F. L., Clarke, A. D., and Kapustin, V.: New particle formation in the remote troposphere: A comparison of observations at various sites, Geophys. Res. Letts., 26, 307-310, 1999.

Vesala, T. E. A.: Long-term field measurements of atmospheresurface interactions in boreal forest combiding forest ecology, micrometeorology, aerosol physics and atmospheric chemistry, Trends Heat Mass Momentum Transf., 4, 17-35, 1998. 